\title{
Assessment of percutaneous intramedullary screw fixation in lateral malleolar ankle fractures
}

\author{
Authors \\ Ahmed Ramadan Darwish*, Mohamed Ibrahim Abulsoud, Adnan Sebaie \\ Orthopaedic and Traumatology Department, Al Azhar University, Egypt
}

\begin{abstract}
Purpose: To evaluate the outcome of using percutanous intramedullary screw and its efficacy on fixation of lateral malleolar ankle fractures.

Methods and Materials: Twenty-five patients with Weber A and Weber B displaced lateral malleolus fractures were retrospectively reviewed after they had done closed reduction and percutaneous internal fixation with an intramedullary fully threaded screw with a washer. A 3.5-mm, fully threaded, selftapping bone screw. The length of the screw varies between $90 \mathrm{~mm}$ and $110 \mathrm{~mm}$, depending on the fracture location and pattern.

Results: All fractures united within an average time to union of $5.86 \pm 1.74$ weeks. There were no deep wound infections or complaints of painful hardware. At latest follow-up, functional results were excellent in 16 patients (64\%) good in 8 patients (32\%), fair in one patient (4\%).

Conclusion: Percutaneous intramedullary screw fixation is a good easy technique in management of lateral malleolar fracture that provides good clinical and radiological results as it is rapid, minimally invasive and without prominent hardware.

Keywords: Ankle Fracture; Lateral Malleolus; Intramedullary Screw.
\end{abstract}

\section{Introduction}

The ankle joint is a weight-bearing joint with minimal tolerance for variation from normal anatomy So The key to successful outcome following an ankle fracture is anatomic restoration $^{[1] .}$ It is universally agreed now that perfect reduction with rigid fixation is the cornerstone in preventing or at least delaying the onset of arthritic changes of the ankle joint after such serious injuries ${ }^{[2]}$. The treatment options for lateral malleolar fractures are either non operative or operative including; cerclage wiring, lag screws, a plate and screws, a hook plate, tension band wiring, axial pins, and axial screws ${ }^{[1-3]}$. Recently, Acumed nail introduced to fix the fibular fracture ${ }^{[4]}$. buttress plate and screws and/or a lag screw, depending on the fracture pattern. These methods provide stable anatomic fixation and results of numerous clinical studies were excellent ${ }^{[3,5,6]}$.

It has been criticized by several authors because of the small amount of overlying soft tissues laterally and patients' complaints of pain over prominent subcutaneous hardware ${ }^{[7-9] .}$

Among other different methods of lateral malleolus fixations as an intramedullary fixations using Steinmann pins ${ }^{[10]}$ and Rush rods ${ }^{[1]}$, however, the concern about the hardware backing out has limited their usefulness. 
Cancellous screws alone have also been used for fixation of Weber A fibula fractures ${ }^{[11,12]}$, but, as with smooth pins, these fixation devices may allow rotation of the distal fragment. Several authors have described fixation of fibular fractures with an axial screw ${ }^{[14,15]}$.

At our study which was carried out at $\mathrm{Al}$ azhar university hospitals and at Alamerya general hospital, internal fixation was done for Weber A and Weber $\mathrm{B}$ fibular fractures with a long intramedullary screw for different fracture patterns. It has been utilized because it is felt that this technique is simpler than buttress plating as long as it is minimally invasive and with less hardware complications. The long intramedullary screw also allows better purchase within the fibular canal than a smooth pin (while accommodating the distal fibular lateral bow), therefore eliminating hardware migration ${ }^{[5]}$. Furthermore, Bankston et al. demonstrated biomechanically that this particular fixation device was superior in strength, although not statistically followed up compare to other fixations with plate and screws ${ }^{[15] .}$ They re-ported their clinical results using open reduction and internal fixation of lateral malleolus fractures with an in- tramedullary screw, which demonstrated stable fracture fixation (allowing early weight bearing) and a $100 \%$ rate of union in their series.

Tamara D. Ray, at all, used intramedullary screw fixation for lateral malleolus fracture in 24 patients and they have good results ${ }^{[16]}$.

\section{Patients}

The material of this study included 25 patients with Weber A or B lateral malleolus fractures (transverse or short oblique or spiral patterns) managed by closed reduction and percutaneous internal fixation with an intramedullary, $3.5 \mathrm{~mm}$, fully threaded, self- tapping screw with a washer at El-Amrya Hospital and at AL Azar university hospital from July 2018 to January 2019. The duration of follow up was at least 6 months. other patients with weber $\mathrm{C}$ lateral malleolus fractures or those with associated syndesmotic injury or those

with comminuted fibular fractures were excluded from our study. Their mean age was 45.7 years old. There were 17 males and 8 females. 22 patients had isolated lateral malleolus fractures, the other 3 patients had associated medial malleolus fractures. No posterior malleolar fractures required fixation in this group.

\section{Surgical Technique}

Spinal anaesthesia was given to all patients. The use of a tourniquet was not needed. But, it was required only if associated open medial malleolar fracture fixation. Image intensification was used to aid closed reduction by inverting the foot and then achieving and maintaining fracture reduction with a pointed bone- holding clamp percutaneously. A $1 \mathrm{~cm}$ incision was made just distal to the tip of the lateral malleolus and proceeding distally. A hole was made in the tip of the lateral malleolus with a $2.5 \mathrm{~mm}$ drill bit trying to be somewhat posterior on the lateral malleolus tip. Fig(1) showing a good entry at anteroposterior and lateral views.

AP

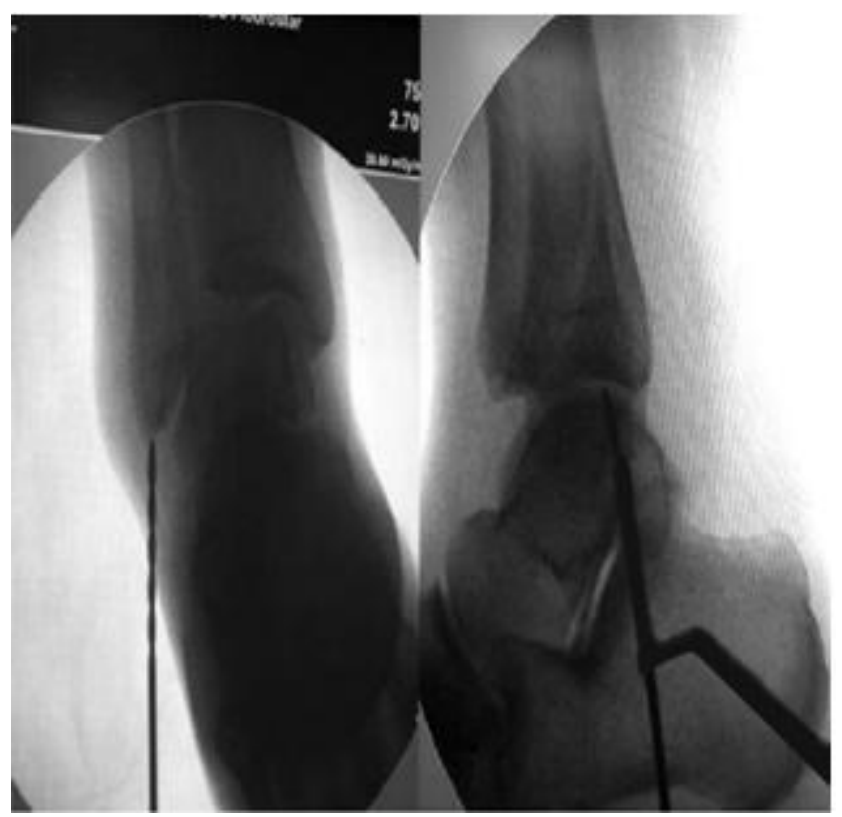

Fig (1) drill hole entry at AP: anteroposterior, and Lat:lateral views

A cortical, $3.5 \mathrm{~mm}$, fully threaded, self-tappin bone screw with a washer was passed across the fracture site and into the proximal fibular fragment.

The screw was tightened until its head reached the 


\section{JMSCR Vol||07||Issue||09||Page 673-680||September}

bone (figure 30). It was not possible to make more compression at the fracture site by further tightening of the screw because it was a fully threaded screw and serrations were on both sides of fracture site. The screw bent with the long axis of distal fibula while accommodating the distal fibular lateral bow.

The length of the screw varies between $90 \mathrm{~mm}$ and $110 \mathrm{~mm}$, depending on the fracture location and pattern. Intraoperative imaging (AP, lateral, mortise) was always obtained to confirm the reduction of the fracture, the position of the screw. The wound was closed with one interrupted suture and gauze dressing. Short leg cast in neutral position was applied for six weeks. Non weight bearing ambulation was allowed according to the fracture pattern and associated injuries and guided by the follow-up X-rays . Fig $2 \mathrm{a}$ and $2 \mathrm{~b}$ showing examples of lateral malleolus fracture fixed by intramedullary screw. also fig $3 \mathrm{a}$ and $3 \mathrm{~b}$ shows another example for weber $b$ lateral malleolus fracture.
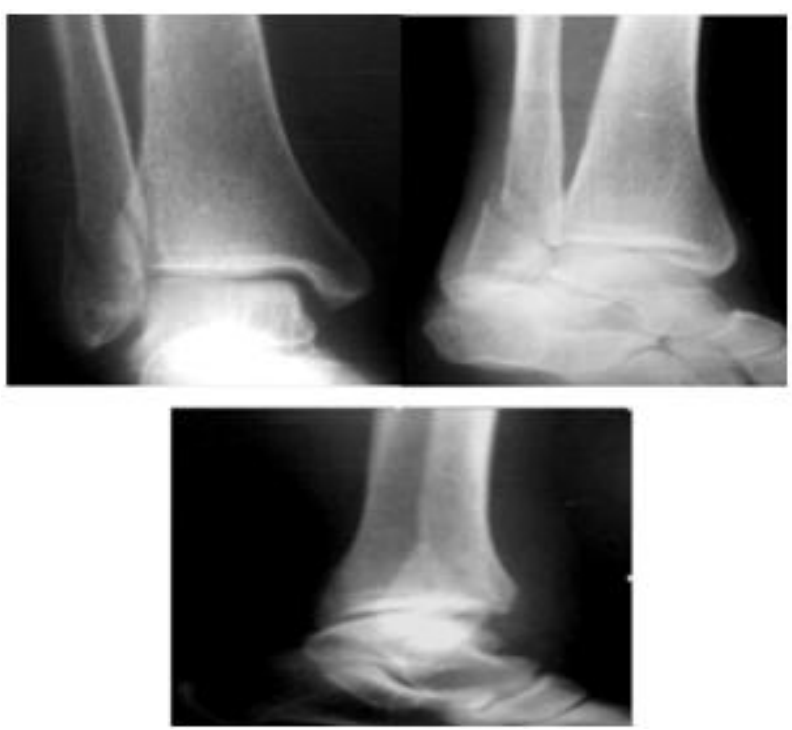

Fig 2a: preoperative $\mathrm{x}$-ray in AP, Lateral and mortise views
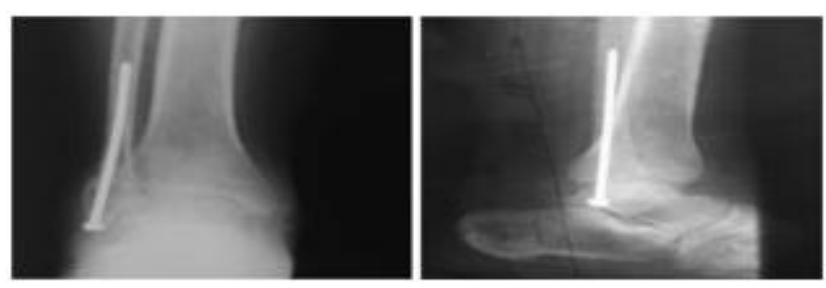

Fig 2b: postoperative $x$ rays
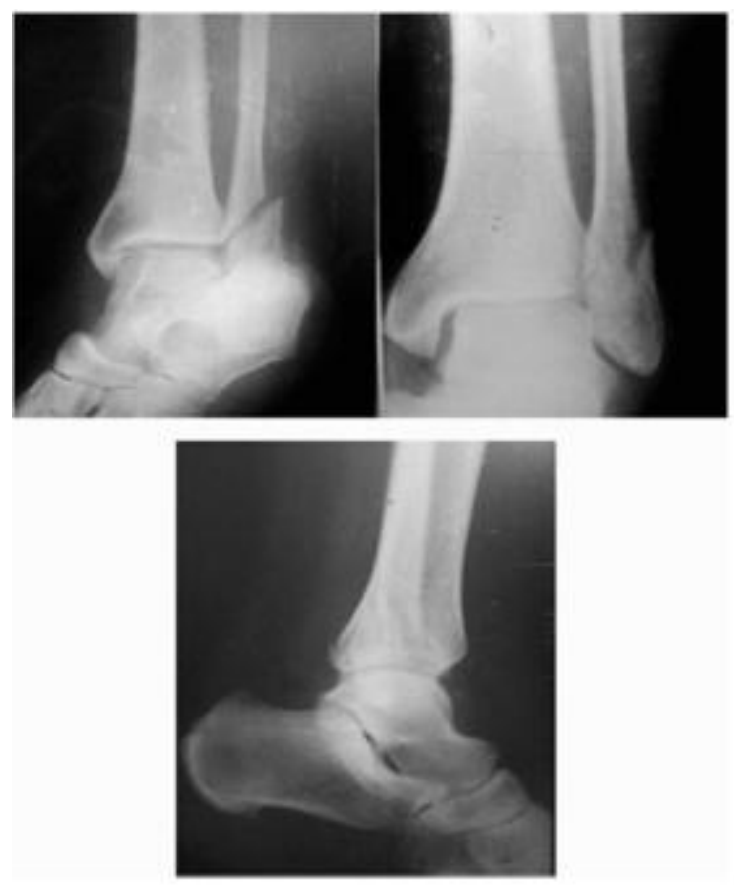

Fig 3a preoperative $\mathrm{x}$ rays in $\mathrm{AP}$, lateral and mortise views

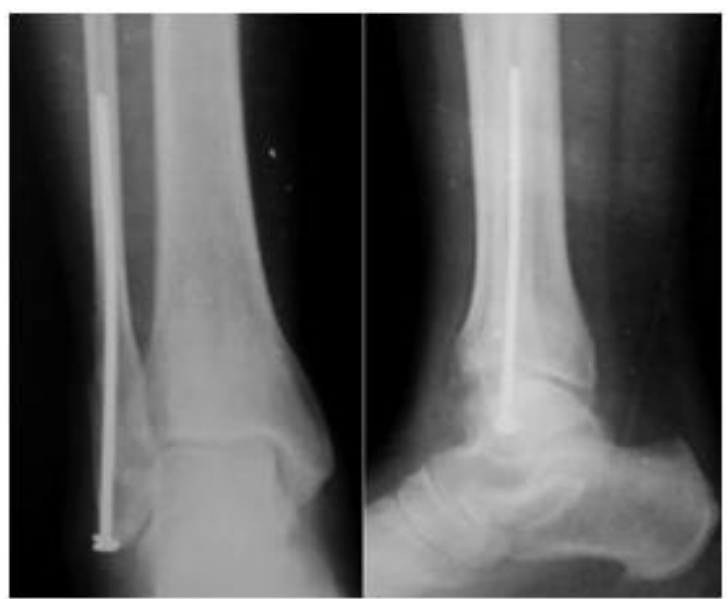

Fig 3b: postoperative $\mathrm{x}$ rays

\section{Results}

20 patients had their ankle fractured due to twisting injury of the ankle when falling down , while 5 patients were due to road traffic accidents (RTA)

The results were assessed both clinically and radiologically at the end of the follow- up period. Olerud and molender for ankle scoring system was used to subjectively evaluate ankles by the patients. The mean of the olerud and molender score was $93 \pm 8.717$. The overall results were considered as satisfactory in 24 patients $(96 \%)$ and unsatisfactory in one patient (1\%). All the 
cases were united with union rate $100 \%$. Nineteen patients $(76 \%)$ had a united fracture in 6 weeks or less and six patients $(24 \%)$ had a united fracture in 8 weeks. The average time of union was $5.86 \pm$ 1.74 weeks, ranging from 4 to 8 weeks.

One patient $(5 \%)$ had a superficial infection at the site of incision and one patient (5\%) had malunited lateral malleolus fracture in the form of rotation. No patients had a deep infection, non union, joint stiffness or painful prominent hardware.

\section{Discussion}

Stable, anatomic fixation of the lateral malleolus fragment is highly appreciated to achieve satisfactory results in ankle fractures.

Yablon pointed out that the talus follows the lateral malleolus and Harper showed that relatively minor lateral malleolus fractures allow for talar shift and joint incongruity. ${ }^{(17)}$

Various methods of lateral malleolar fixation have been utilized, all with acceptable results. The most common method of fixation of lateral malleolar fractures is the buttress plating andlor a lag screw. It provides stable fixation and maintains length of the lateral malleolus.It is preferred in cases where the malleolus is comminuted, as length could not be reliably maintained with an intramedullary screw as well as fractures with syndesmotic injury where syndesmotic screw is needed (Weber type C). The complications of plate fixation of the lateral malleolus are wound healing, especially in swollen ankles and painful prominent hardware often develop late. Reduction of the fracture may be done in closed or open manner. ${ }^{(18)}$ Advantages of closed reduction include minimal soft-tissue dissection, short operative time, no need of tourniquet if isolated lateral malleolus fractures, improved healing and shortened rehabilitation time because the fracture hematoma is not violated $^{\text {(13) }}$

The long intramedullary screw allows to get purchase within the fibular canal, therefore eliminating hardware migration. The intramedullary position allows for dynamic compression at the fracture site with weight bearing, thus facilitating fracture healing. ${ }^{(15)}$ The slight flexibility of the axial screw allows it to easily accommodate the distal fibular bow, resulting in three-point fixation of the fracture, as the lateral malleolus is normally in 10 to 15 degrees of valgus in relation to fibular shaft ${ }^{(18)}$

A biomechanical study by Bankston et al for evaluation of intramedullary screw versus buttress plate and lag screw. The fractures were fixed with one of the two above fixation methods and then placed under a torsional load to failure. It was found that the intramedullary screw provided $66.5 \%$ of the strength of native bone compared to the lateral buttress plate provided $61.5 \%$. This was not statistically significant, but it did prove that an intramedullary screw provides stable fixation. So, rehabilitation can be started early without the risk of loss of reduction. (15)

This study includes the postoperative evaluation of closed reduction and percutaneous internal fixation of unstable lateral malleolus fractures Weber types A or B with an intramedullary, 3.5 $\mathrm{mm}$, fully threaded, self-tapping screw with a washer. Regarding the final results, $64 \%$ of patients had excellent results, 32\% had good results and $4 \%$ had fair results. The mean of the score was $93 \pm 8.717$ ranging from 60 to 100 .

The results of this study are comparable with the results of Ray TD et al study which included 24 patients treated with closed reduction and percutaneous internal fixation with an intramedullary, fully threaded, self-taping screw. At final follow-up, $42.1 \%$ had excellent result, $42.1 \%$ had good result, $5.3 \%$ had fair result and $10.5 \%$ had poor result ${ }^{(18)}$

The results of the present study are also comparable with the results of Latif $\mathrm{G}$ et al study which included 46 patients with Weber A and low Weber B displaced lateral malleolus fractures who underwent closed reduction and percutaneous internal fixation with an intramedullary, $3.5 \mathrm{~mm}$, fully threaded, self-tapping bone screw were retrospectively reviewed. At latest follow-up, results were excellent in 25 patients $(54.3 \%)$, good 
in 20 patients $(43.5 \%)$ and fair in one patient $(2.2 \%){ }^{(13)}$

In the present study the average time of union was $5.86 \pm 1.74$ weeks, ranging from 4 to 8 weeks with union rate $100 \%$. While in the study of Ray TD et al, the average time of fracture union was 8.2 weeks with one case developed nonunion, with a union rate $95.5 \%$. The average time of full weight bearing was 6.8 weeks and in patients with isolated lateral malleolus fractures time decreased to 4.5 weeks. The same results in the study of Latif $\mathrm{G}$ et al, the average time of union was 8.2 weeks. The average time to full weight bearing was 6.8 weeks, whereas that in patients with isolated lateral malleolus fractures was 4.5 weeks.

Regarding the use of tourniquet, in the present study no tourniquet is used, except in the three cases with associated medial malleolar fractures who underwent open reduction and internal fixation.Medial malleolus fracture was fixed by 2 cancellous screws in two patients while the third patient had his medial malleolus fixed with a plate and screws.

In the study of Ray TD et al and Latif G et al, using this percutaneous technique, the use of tourniquet is optional and they didn't report the use of tourniquet in isolated lateral malleolus fractures. But in the study of Kim HJ et al, who used a $3.5 \mathrm{~mm}$ T-shaped locking compression plate, the conventional lateral approach was utilized to expose the lateral malleolus under tourniquet and they didn't report any postoperative tourniquet complications. ${ }^{(19)}$ In the study of Lamontagne $\mathrm{J}$ et al, who used the lateral plate and antiglide plate techniques, all the cases are operated under tourniquet, despite of all of them are isolated lateral malleolus fractures. The mean tourniquet time in group 1 treated with lateral plate was 48.5 minutes and in group 2 treated with antiglide plate was 44.3 minutes, also they didn't report any postoperative tourniquet complications. $^{\text {(20) }}$

The use of tourniquet may lead to many complications as Nerve injury which is the most common complication. It can range from mild transient loss of function to irreversible damage and paralysis. Other complications of tourniquet are arterial injury due to indirect trauma and thrombosis, tourniquet pain, compartment syndrome, pressure sores, deep venous thrombosis leading to pulmonary or venous embolization. High pressures and forgotten digital tourniquets can lead to severe ischemic injuries of the digits. ${ }^{(21)}$

The length of the screw used in the present study ranging from $90 \mathrm{~mm}$ to $110 \mathrm{~mm}$. In the study of Ray TD et al, the length of the screw ranging from 2.5 inches to 4 inches $(62.5 \mathrm{~mm}$ to $100 \mathrm{~mm}$ ) depending on fracture location, pattern and the width of the medullary canal proximal to the fracture site. While Latif $\mathrm{G}$ et al reported that the length of the screw varied between $100 \mathrm{~mm}$ and $120 \mathrm{~mm}$, depending on the fracture location and pattern. In this study, the length of the screw didn't affect the final results.

The small set $3.5 \mathrm{~mm}$ screw used in this study was long enough to get a purchase within the fibular medullary canal, with available screw length measures ranging from $60 \mathrm{~mm}$ to $120 \mathrm{~mm}$. The flexibility of the $3.5 \mathrm{~mm}$ screw allowed it to accommodate the distal fibular bow, resulting in three-point contact within the fibular medullary canal. The small set $4.0 \mathrm{~mm}$ screw, either fully threaded or partially threaded, didn't have available length measures to get a purchase in the fibular medullary canal. The standard $6.5 \mathrm{~mm}$ screw, either fully threaded or partially threaded, is a rigid screw and not flexible to accommodate the distal fibular bow. So, the $4.0 \mathrm{~mm}$ and $6.5 \mathrm{~mm}$ screws can't be used in this study.

The age and sex of the patients had no significant correlation with the final results, which was proven in this study and other studies which were done by other authors. $(13,18)$

Of the twenty-five patients in the present study, three patients had associated medial malleolus fractures. While in the study of Ray TD et al, five patients had an associated medial malleolar fractures and one patient had a trimalleolar fracture. Two of the patients with associated 
medial malleolus fractures had an unsatisfactory result, one patient with fair score had a malunited medial malleolus and one patient with poor score had a nonunited medial malleolus. But in the study of Latif $G$ et al, fifteen patients had an associated medial malleolus fractures and ten patients had a trimalleolar fracture. They didn't report the correlation between associated medial malleolus fractures and the final score. In the study of Kim $\mathrm{HJ}$ et al, eleven patients had associated medial malleolar fractures. Also, they didn't report the correlation between associated medial malleolus fracture and the final score. The study of Lamontagne $\mathbf{J}$ et al was on isolated lateral malleolus fractures.

In this study,three patients had associated medial malleolus fracture.Two of them had satisfactory results ,the remaining one had a fair score with mild pain and edema with activities of daily living and was able to walk the desired distance with mild limp despite the full range of motion of ankle joint.

In the present study no single case complicated with nonunion. But, one patient had malunited lateral malleolus fracture in the form of rotation. Rotation occurred during screw head tightening at the end of its insertion which might be due to early removal of the bone holding clamp with partial loss of fracture reduction. In this study, malunion didn't affect the final results. While in the study of Ray TD et al, one patient with fair score who had a shortened lateral malleolus $\leq$ $2 \mathrm{~mm}$. Another patient with poor score who developed nonunion, which was internally fixed in distraction during ipsilateral closed intramedullary tibial nailing and was managed later on by bone graft and plating. In the study of Latif $\mathrm{G}$ et al, one patient, who had fair score, developed malunited lateral malleolus in the form of shortening.

The overall infection rate in the present study was $4 \%$, which were two patients with a superficial infection managed by daily dressing and adequate antibiotic. When compared to the study of Ray TD et al, One patient (4.2\%) developed minor wound complication in the form of mild serous discharge from operative site at the time of cast removal which respond to conservative management. No superficial or deep infection was reported in the study of Latif $\mathrm{G}$ et al.

In the study of Lamontagne $\mathrm{J}$ et al, who used the lateral plate and antiglide plate techniques, eleven patients had wound infection with infection rate $5.7 \%$. Nine of them had a superficial infection and two of them had a deep infection. One of them treated with surgical debridement and an antibiotic bead pouch technique and the wound was closed with removal of the bead pouch, five days later. The second patient had a chronic infection. A wound dehiscence and a reflex sympathetic dystrophy complicated the early postoperative period. The plate was removed after two years to control an open draining sinus. While in the study of Kim $\mathrm{HJ}$ et al, no infection rate was reported despite the cases was treated with open internal fixation with lateral skin incision.

The present study and the studies of Ray TD et al and Latif $G$ et al had a low infection rate when compared to the study of Lamontagne $\mathrm{J}$ et al, this might be due to the closed reduction method and the percutaneous technique in fixation of lateral malleolus fractures through just a $1 \mathrm{~cm}$ skin incision without interruption of soft tissue like the traditional lateral skin incision in open internal fixation.

Of the twenty-five cases in the present study, the studies of Ray TD et al and Latif $\mathrm{G}$ et al, no one had a painful, prominent screw or peroneal tendinitis due to the intramedullary position of the screw. In Kim $\mathrm{HJ}$ et al study, there were no peroneal tendinitis. But, six cases $(23.1 \%)$ had implant irritation over the operative site.

In laterally applied plates hardware related problems were more common. Brown et al reported that $31 \%$ of patients had hardware related pain and that $23 \%$ of patients required hardware removal, $50 \%$ of those patients who had their hardware removed reported improvement and decrease in pain score. ${ }^{(22)}$

Jacobsen et al reported that $66 \%$ of patients with a lateral plate had implant related complaints that 
led to removal of implants. $75 \%$ of these patients had relief after removal. ${ }^{(23)}$ Tornetta and Creevy also reported that $56 \%$ of patients with a lateral plate had complaints of palpable hardware, $17 \%$ had pain related to the plates, $15 \%$ had restriction in movements and $31 \%$ required removal of implants. ${ }^{(24)}$

Ostrum reported no wound problems, no palpable hardware, no nonunion or implant problems but noticed transient peroneal tendinitis in 4 patients and only 2 patients required removal of implant in posterior plating of displaced fibula fractures. ${ }^{(25)}$ Furthermore $43 \%$ of plates were removed because of peroneal tendonitis in Weber and Kraus. ${ }^{(26)}$

The results of this study, which was also supported by many other studies proved that percutaneous fixation gave good clinical results in management of lateral malleolus fractures Weber types A or B with minimal complication rate and doesn't need another surgery for hardware removal. ${ }^{(13,18)}$

\section{Conclusion}

Percutaneous intramedullary screw fixation gave good clinical and radiological results in management of lateral malleolus fractures Weber A or B with transverse or short oblique or spiral patterns without prominent subcutaneous hardware.

\section{References}

1. Koval KJ. Bimalleolar ankle fractures: open reduction and internal fixation. In: Atlas of orthopaedic surgery. Koval KJ, Zuckerman JD. $1^{\text {st }}$ ed. Philadelphia. Lippincott Williams \& Wilkin 2004;1(23):353-71.

2. White TO, Bugler KE. Ankle fractures. In: Rockwood and Green's Fractures in Adult. Court-Brown CM, Heckman JD, McQueen MM, Ricci W, Tornetta III P, McKee M. $8^{\text {th }}$ ed. Wolters Kluwer Health. 2015;2 (59):2541-92.

3. Makwana NK, Bhowal B, Harper WM, Hui AW. Conservative versus operative treatment for displaced ankle fractures in patients over 55 years of age. J Bone Joint Surg (Br) 2001;83(4):525-9.

4. Goost H, Wimmer MD, Barg A, Kabir K, Valderrabano V, Burger C. Fractures of the ankle joint, investigation and treatment options. Dtsch Arztebl Int 2014;111 (21):377-88.

5. Rammelt S. Management of ankle fractures in the elderly. EFORT Open Rev 2016;1(5): 239-46.

6. Bugler KE, Watson CD, Hardie AR, Appleton P, Mcqueen MM, Court-Brown $\mathrm{CM}$, et al. The treatment of unstable fractures of the ankle using the acumed fibular nail. J Bone Joint Surg (Br) 2012; 94(8):1107-12.

7. Mehta SS, Rees K, Cutler L, Mangwani J. Understanding risks and complications in the management of ankle fractures. Indian $\mathbf{J}$ Orthop 2014;48(5):445-52.

8. Soo Hoo NF, Krenek L, Eagan MJ, Gurbani B, Ko CY, Zingmond DS. Complication rates following open reduction and internal fixation of ankle fractures. J Bone Joint Surg (Am) 2009; 91(5):1042-9.

9. White TO, Bugler KE, Appleton P, Will E, McQueen MM, Court-Brown CM. A prospective randomised controlled trial of the fibular nail versus standard open reduction and internal fixation for fixation of ankle fractures in elderly patients. J Bone Joint Surg (Br) 2016;98(9):1248-52.

10. Evans JM, Gardner MJ, Brennan ML, Phillips CJ, Henley MB, Dunbar RP. Intramedullary fixation of fibular fractures associated with pilon fractures. J Orthop Trauma 2010;24(8):491-4.

11. Olerud C, Molander H, Olsson T, Hagstedt B. Ankle fractures treated with non- rigid internal fixation. Injury 1986;17(1):23-7.

12. Pritchett JW. Rush rods versus plate osteosyntheses for unstable ankle fractures in the elderly. Orthop Rev 1993;22(6):6916.

13. Latif G, Al-Saadi H, Zekry M, Hassan M, 
Mulla J. The effect of percutaneous screw fixation of lateral malleolus on ankle fracture healing and function. Surgical Science 2013; 4(8):365-70.

14. Covino BM, Barsanti CM, Wolfe J, Wang GJ. Internal fixation of lateral malleolus fractures: a clinical and biomechanical comparison of two techniques. Orthop Trans 1990; 5:90.

15. Bankston AB, Anderson LD, Nimityongskul P. Intramedullary screw fixation of lateral malleolus fractures. Foot Ankle Int 1994; 15(11):599-607.

16. T. D. Ray, P. Nimityongskul and L. D. Anderson, "Per-cutaneous Intramedullary Fixation of Lateral Malleolus Fractures: Technique and Report of Early Results," Journal of Trauma, Vol. 36, No. 5, 1994, pp. 669-675.

17. Yablon IG, Heller FG, Shouse L. The key role of lateral malleolus in displaced fractures of the ankle. J Bone Joint Surg (Am) 1977;59(2):169-73.

18. Ray TD, Nimityongskul P, Anderson LD. Percutaneous intramedullary fixation of lateral malleolus fractures: Technique and report of early results. J Trauma 1994;36(5):669-75

19. Kim HJ, Oh JK, Hwang JH, Park YH. The use of T-LCP (locking compression plate) for the treatment of the lateral malleolar fractures. Eur J Orthop Surg Traumatol 2013;23(2):233-7.

20. Lamontagne J, Blachut PA, Broekhuyse HM, O'Brien PJ, Meek RN. Surgical treatment of a displaced lateral malleolus fracture: the antiglide technique versus lateral plate fixation. J Orthop Trauma 2002;16(7):498-502.

21. Sharma JP, Salhotra R. Tourniquets in orthopedic surgery. Indian $\mathrm{J}$ Orthop 2012;46(4):377-83.

22. Brown OL, Dirschl DR, Obremskey WT. Incidence of hardware-related pain and its effect on functional outcomes after open reduction and internal fixation of ankle fractures. J Orthop Trauma 2001;15(4):2714.

23. Jacobsen S, Honnens de Lichtenberg $\mathbf{M}$, Jensen CM, Torholm C. Removal of internal fixation--the effect on patients' complaints: a study of 66 cases of removal of internal fixation after malleolar fractures. Foot Ankle Int 1994;15(4):170-1.

24. Tornetta P III, Creevy W. Lag screw only fixation of the lateral malleolus. J Orthop Trauma 2001;15(2):119-21.

25. Ostrum RF. Posterior plating of displaced Weber B fibula fractures. J Orthop Trauma 1996;10(3):199-203.

26. Weber M, Krause F. Peroneal tendon lesions caused by antiglide plates used for fixation of lateral malleolar fractures: the effect of plate and screw position. Foot Ankle Int 2005;26(4):281-5. 